\title{
Improved Clinical Competence and Patients Satisfaction: Comparison of Patient-centered, Interdisciplinary Collaborative Round versus Traditional Post-partum Round
}

\author{
Arshia Javed ${ }^{1}$, Arjumand Sohaila ${ }^{2}$, Irfan Sheikh $^{1}$ and Nida Qadir ${ }^{1}$ \\ ${ }^{1}$ Department of Obstetrics and Gynecology, The Aga Khan University Hospital, Karachi, Pakistan \\ ${ }^{2}$ Department of Pediatrics, The Aga Khan University Hospital, Karachi, Pakistan
}

\begin{abstract}
The origin of the patient-centered interdisciplinary collaborative round, which involves health care members of all levels at a time, is an effective and emerging approach to offer inpatient healthcare. Traditionally, post-partum rounds at teaching hospitals consisted of separate visits from all members of the obstetric team that resulted in patient inconvenience, care insufficiencies, and communication gaps. The main objective of this study was to assess the patient's satisfaction level from the traditional post-partum round versus the patient-centered collaborative care (PCCC) round. This study showed that in the traditional round, the patient's satisfaction with the treatment was $95.1 \%$; whereas, in PCCC rounds it was $96.9 \%$. Patients were more satisfied with the treatment options discussed with them and the results of the medical tests explained to them. In conclusion, the survey showed that the implementation of the PCCC round improved patient satisfaction.
\end{abstract}

\section{Key Words: Interdisciplinary collaborative round, Traditional postpartum round, Patients satisfaction, Clinical competence.}

How to cite this article: Javed A, Sohaila A, Sheikh I, Qadir N. Improved Clinical Competence and Patients Satisfaction: Comparison of Patient-centered, Interdisciplinary Collaborative Round versus Traditional Post-partum Round. J Coll Physicians Surg Pak 2021; 31(07):868-870.

An important indicator to assess the standard of healthcare is patient's satisfaction, which can also be used as quality improvement tool for healthcare institutions. ${ }^{1}$ Reports like ‘To Err is Human-Building a Safer Health Care System' emphasised the need for innovations in delivery of high-quality care that is patient-centered. ${ }^{2}$ Among such innovations, origin of interdisciplinary collaborative rounds, which involves nurses, physicians, quality officers, admin representatives as well as learners of all levels at a time, is an effective and emerging approach to offerinpatient healthcare. ${ }^{3}$

Traditionally, post-partum rounds at teaching hospitals consisted of separate visits from all members of the obstetric team individually including nurses, medical students, residents, attending physicians, quality improvement and patient safety officers (QIPS). This resulted in patient inconvenience, dissatisfaction, care insufficiencies and communication gaps. ${ }^{3}$

Correspondence to: Dr. Irfan Sheikh, Department of Obstetrics and Gynecology, The Aga Khan University Hospital, Karachi, Pakistan

E-mail: sheikh.irfan@aku.edu

Received: March 06, 2020; Revised: February 10, 2021; Accepted: February 25, 2021

DOI: https://doi.org/10.29271/jcpsp.2021.07.868
The majority of the literature on this matter is from United States and other high-income countries (HICs). Much remains unknown in low- and middle-income countries (LMICs), including Pakistan. Few earlier studies were conducted regarding patient's satisfaction, but efficiency of patient-centered collaborative care (PCCC) in health delivery system was not evaluated locally, resulting in a dearth of local literature regarding this important topic.

Thus, to improve the culture of teamwork in a local teaching hospital, a quality improvement (QI) project was designed and evaluated in a local secondary care hospital that included not only physicians and doctors but also nurses, pharmacists, paramedical staff and QIPS officers, into daily bedsides morning rounds. Pre-intervention and post-intervention surveys were conducted to assess patient's satisfaction level in order to assess whether a paradigm shift from traditional post-partum round to PCCC round would improve clinical efficiency and patient's satisfaction.

This study is first of its type that examines the PCCC approach in local healthcare settings. The main objective of this study was to assess the patient's satisfaction level from traditional post-partum round versus PCCC round.

This was a cross-sectional study, conducted from June 2017 to February 2018, at one of the secondary care settings of the Aga Khan University Hospital for Women, Garden, Karachi. 
Table I: Responses by patients $(\mathrm{N}=145)$.

\begin{tabular}{|c|c|c|c|}
\hline \multirow{2}{*}{ Questions asked } & \multicolumn{2}{|c|}{$\begin{array}{c}\text { Numbers of patients who agreed to the } \\
\text { questions asked }\end{array}$} & \multirow{2}{*}{ p-value } \\
\hline & $\begin{array}{l}\text { Traditional Round } \\
\quad \mathbf{N}=\mathbf{8 1}(\%)\end{array}$ & $\begin{array}{l}\text { PCCC Round } \\
\mathrm{N}=64(\%)\end{array}$ & \\
\hline Team greeted me & $80(98.8)$ & $64(100)$ & 0.999 \\
\hline I was called by my name & $79(97.5)$ & $63(98.4)$ & 0.999 \\
\hline Team showed interest in my problem & $76(93.8)$ & $64(100)$ & 0.129 \\
\hline I was explained about my condition & $76(93.8)$ & $63(98.4)$ & 0.229 \\
\hline Treatment options were discussed & $75(92.6)$ & $64(100)$ & $0.034 *$ \\
\hline Reasons for medical tests were explained & $66(81.5)$ & $61(95.3)$ & $0.026 *$ \\
\hline Team communicated with me in understandable language & $76(93.8)$ & $62(96.9)$ & 0.537 \\
\hline I was given adequate time by team & $75(92.6)$ & $63(98.4)$ & 0.128 \\
\hline I feel treated with respect & $76(93.8)$ & $62(96.9)$ & 0.089 \\
\hline I am satisfied with my treatment & $77(95.1)$ & $62(96.9)$ & 0.292 \\
\hline I am satisfied with nursing care & $65(80.2)$ & $62(96.9)$ & $0.007 *$ \\
\hline I would like to visit this hospital again & $72(88.9)$ & $62(96.9)$ & 0.099 \\
\hline I will recommend this hospital to others & $68(84.0)$ & $64(100)$ & $0.001^{*}$ \\
\hline
\end{tabular}

The data was collected on a structured questionnaire adapted from previously used survey tools. ${ }^{3}$ The study included all the patients admitted in post-natal ward for at least two days after delivery from $20^{\text {th }}$ June to $19^{\text {th }}$ July 2017 (pre-intervention survey) and for one month from $1^{\text {st }}$ February to 28th February 2018 (post-intervention survey) after PCCC rounds that has been placed for 6 months from August 2017 to January 2018. A total of 145 women were included in this analysis; 81 of them participated in traditional post-partum rounds and 64 participated in PCCC rounds. The survey form was given to consented post-partum patients at the time of discharge, who were admitted during study course. The obtained information from pre-intervention survey was then compared with the information collected from post-intervention survey.

Descriptive statistics was carried out to analyse the data by calculating the frequencies and percentages for the categorical variables. Chi-square and Fisher's Exact test were further applied to evaluate the responses of survey questions for those patients included in the traditional rounds, compared to those included in the PCCC rounds. A p-value of $\leq 0.05$ was considered statistically significant. The data was analysed using Statistical Package for the Social Sciences (SPSS) version 19 (SPSS Inc., Chicago, IL). The study was approved by the Ethics Committee of the Aga Khan University Hospital.

A total of 145 women were included in this analysis; $81(55.9 \%)$ of them participated in traditional post-partum rounds and 64 (44.1\%) participated in PCCC rounds. Maternal age, parity, literacy and occupation were comparable between patients included in traditional and PCCC rounds. The demographic data of patients in traditional round showed that majority of the respondents were of age $<31(76.5 \%)$ years followed by $>30(23.5 \%)$ years. About $1.2 \%$ respondents were uneducated followed by primary level $(6.2 \%)$, secondary level $(48.1 \%)$ and gradua- tion $(44.4 \%)$. In the study, $91.4 \%$ of the respondents were housewives, $95.1 \%$ had parity of less than four, while $(4.9 \%)$ had parity of more than four. Whereas, in PCCC round, majority of respondents were of age $<31(67.1 \%)$ and $>30(32.8 \%)$ years. About $7.8 \%$ respondents were uneducated followed by primary level (3.1\%), secondary level $(40.6 \%)$ and graduation (48.4\%). In all, $82.8 \%$ of the respondents were housewives, $96.9 \%$ of patients had parity of less than four, while $3.1 \%$ had parity of more than four.

Table I shows that in traditional round the patient's satisfaction with the treatment was $95.1 \%$; whereas, in PCCC rounds it was $96.6 \%$. A difference of $1.6 \%$ was observed, although higher level of satisfaction was reported in the study by Qadri; ${ }^{4}$ and $89.1 \%$ of the patients were satisfied with PCCC rounds. In traditional round, $80.2 \%$ of the patients were satisfied with the nursing care; whereas, with PCCC round the satisfaction level raised to $96.9 \%$. These findings are similar with the study conducted by Bitew. ${ }^{5}$ In PCCC round, $100 \%$ respondents were satisfied with the interest showed by the team in their problems; whereas, in traditional round $93.8 \%$ respondents were satisfied.

In traditional round, $93.8 \%$ of the patients were satisfied with the disease explanation given to them, $92.6 \%$ reported that alternate treatment options were given to them, and $81.5 \%$ were explained about rationale of medical tests. While for PCCC round, $98.4 \%$ patients were satisfied with disease explanation, $100 \%$ of the patients with the alternate treatment options and $95.3 \%$ with the reasoning of medical tests. These finding are also similar to the study by Bitew, ${ }^{5}$ in which satisfaction with explanation about treatment was reported in $92.3 \%$.

In traditional round, $88.9 \%$ patients provided the preference to visit the same hospital again and $84 \%$ suggested that they would like to recommend this to others; while in PCCC round $96.9 \%$ patient exhibited their willingness to visit same 
hospital again and majority recommended this facility to others. This is comparable to the study by Nisa, ${ }^{6}$ where $98 \%$ patients recommended same facility to others.

Patient satisfaction is an important factor in the patient care and management. The assessment of patient satisfaction through surveys and their outcome data help in monitoring quality of care and planning and implementing strategies to improve patient care. This survey showed that implementation of PCCC round improved patient satisfaction. Patients were more satisfied with the treatment options discussed with them and results of the medical tests explained to them, they showed more satisfaction with the nursing care and provided their preference to visit the same hospital again and to recommend it to others.

Hence, this study specifies that PCCC round improves clinical efficiencies with team work as well as effective communication between team members. PCCC round brought the opportunity of actively and mutually evaluating the patient and medical team member's interactions in such a way that necessary clinical, academic and administrative adjustments in the best interest of patient and hospital are made with secure coordination and competency among team members.

\section{ACKNOWLEDGEMENT:}

The authors acknowledge Ms. Ghulam Kubra Rind (Senior Research Assistant, Department of OBGYN, Aga Khan University Hospital) for her support in editing of this manuscript.

\section{ETHICAL APPROVAL:}

The ethical approval was obtained by the Ethics Review Committee of the Aga Khan University Hospital prior to initiation of the research work.

\section{PATIENTS' CONSENT:}

Written informed consents were taken from the participants prior to data collection.

\section{CONFLICT OF INTEREST:}

The authors declared no conflict of interest.

\section{AUTHORS' CONTRIBUTION:}

A): Conceptualisation of topic, designed, literature search, manuscript writing, and editing of manuscript.

AS: Literature search, data collection and manuscript writing.

IS: Statistical analysis, proofreading, review and final approval of manuscript. responsible and accountable for the accuracy or integrity of the work.

NQ: Data collection and interpretation of results.

\section{REFERENCES}

1. Kanwal K, Rafi Y, and Sarwar ZM. Patient experiences and satisfaction at tertiary care setting in Public Hospital in Pakistan. PJMHS 2019; 13(1):115-7.

2. Markova T, Mateo M, Linda M. Implementing teams in a patient-centered medical home residency practice: Lessons learned. J AM board Fam Med 2012; 25(2): 224-31. doi: 10.3122/jabfm.2012.02.110181.

3. Segel S, Hashima J, Gregury TW, Edelman AA, Li H . A new approach to postpartum rounds: Patient-centered collaborative care improves efficiency. J Grad Med Educ 2010; 21(1):67-72. DOI: 10.4300/JGME-D-09-00060.1

4. Qadri SS, Pathak R, Singh M. An Assessment of patient's satisfaction with services obtained from a tertiary care hospital in rural Haryana. Int J Collab Res Intern Med Public Health 2012; 4(8):1524-37.

5. Bitew K, Ayichiluhm M, Yimam K. Maternal satisfaction on delivery services and its associated factors among mothers who gave birth in public health facilities of Debre Markos Town , Northwest Ethiopia. BioMed Res Int 2015; 2015:1-6. doi: 10.1155/2015/460767.

6. Nisa M, Sadaf R, Zahid M. Patient satisfaction survey in an obstetrics and gynecology ward of a tertiary care hospital. J Med Sci 2012; 20(3):142-5. 